\title{
Case Report: Scientific Dissemination as a Mediator of the \\ Research Consolidation Process: Proposals for \\ Institutionalization [version 1; peer review: awaiting peer
}

\section{review]}

\author{
Tássia Galvão1', Kamilla Assis Tavares¹, Michele Fernandes (iD2, \\ José Carlos Moreira de Souza2, Matias Noll2 \\ 1PROFEPT, IF GOIANO, Morrinhos, Goias, 75650-000, Brazil \\ 2PROFEPT, IF GOIANO, Ceres, Goias, 76300-000, Brazil
}

\author{
V1 First published: 03 Sep 2021, 10:886 \\ https://doi.org/10.12688/f1000research.55655.1 \\ Latest published: 03 Sep 2021, 10:886 \\ https://doi.org/10.12688/f1000research.55655.1
}

\section{Abstract \\ Introduction}

Communicating science is one of the main steps in the research process. However, the method of communication must be aligned with the audience for the message. This is especially evident in institutions that promote teaching, research, and extension, especially when considering joint actions that promote a dialogue between themselves and the community.

\section{Methods}

In light of this need, this study was conducted with the aim of analyzing the main documents guiding the policies and institutional actions related to research at the two federal institutes based in the state of Goiás/Brazil: Institution A and Institution B and proposing ways to include scientific dissemination as a mediator of the research consolidation process. This is a bibliographic, documentary study with a descriptive, qualitative approach based on a case study.

\section{Results and Discussion}

The analyses indicate that research must be consolidated as institutional policy and that a policy to encourage research must be implemented. This has yet to be achieved at these institutions, although scientific dissemination is explicitly addressed by institutional documents guiding the development and dissemination of pedagogical practices, especially in teaching and extension.

Scientific journalism and scientific dissemination are mediators and facilitators of this endeavor.

\section{Keywords}

Scientific journalism, Popularization of science, Educational principles of research, Federal Institute of Education, Science, and Technology.

\section{Open Peer Review}

Approval Status AWAITING PEER REVIEW

Any reports and responses or comments on the article can be found at the end of the article. 
Corresponding authors: Michele Fernandes (michelevaladao_profept@hotmail.com), Matias Noll (matiasnoll@yahoo.com.br)

Author roles: Galvão T: Writing - Original Draft Preparation; Tavares KA: Writing - Review \& Editing; Fernandes M: Writing - Review \& Editing; Souza JCMd: Writing - Review \& Editing; Noll M: Writing - Review \& Editing

Competing interests: No competing interests were disclosed.

Grant information: The author(s) declared that no grants were involved in supporting this work.

Copyright: @ 2021 Galvão T et al. This is an open access article distributed under the terms of the Creative Commons Attribution License , which permits unrestricted use, distribution, and reproduction in any medium, provided the original work is properly cited.

How to cite this article: Galvão T, Tavares KA, Fernandes M et al. Case Report: Scientific Dissemination as a Mediator of the Research Consolidation Process: Proposals for Institutionalization [version 1; peer review: awaiting peer review] F1000Research 2021, 10:886 https://doi.org/10.12688/f1000research.55655.1

First published: 03 Sep 2021, 10:886 https://doi.org/10.12688/f1000research.55655.1 


\section{Introduction}

In Brazil, the core principle of educational institutions, as conceptualized in the law and educational practices, is (or should be) to facilitate a joint effort to promote the development of projects and actions related to teaching, research, and extension. The existence of Federal Institutes of Education, Science, and Technology (IFs), like universities, is based on this premise. Thus, the dynamics of IFs should be considered. They were created with the enactment of Law No. 11.892/2008 on December 29, 2008, which later culminated in the creation of the Federal Network of Professional, Scientific, and Technological Education (Rede Federal de Educação Profissional, Científica e Tecnológica). According to this law the goal of an IF is to offer professional and technological education at all levels and modalities through an educational and investigative process, be a center of excellence in general and applied science teaching, develop scientific extension and dissemination programs, carry out and stimulate the development of applied research, and promote cultural production, entrepreneurship, cooperation, and scientific and technological development, among other objectives.

These institutes rely on documents and practices that consider the inseparability of teaching, research, and extension in the creation of policies. In line with the need to include research and extension in the educational environment, Stecanela and Williamson (2013) argue that discussing research facilitates the promotion of awareness, which, in turn, generates positive attitudes and experiences. This occurs through encouraging students to develop the ability to analyze and evaluate personal experiences, their social realities, and systematized knowledge. Thus, inquiries, hypotheses, and research based on texts from various genres allow the construction and development of argumentation, one of the characteristics of scientific research.

The education that students receive at IFs must necessarily be delivered with the aim of promoting the professional and personal independence of students and their comprehensive development as people as well as autonomy in building their learning experiences and personal histories (Gramsci, 2004). Indeed, this is also the path that must be followed by scientific journalists and communicators, who are at the other end of this dissemination process, when performing their work. The development of autonomy among these mediating professionals in writing and in their dialogue with internal and external communities is necessary. This challenge becomes apparent when they only rely on their scientific sources. Bueno (2019) criticizes this situation. In this scenario, argumentation is part of their journalistic work and, as such, must be emphasized in student training. Another aspect of this approach that should be emphasized is the use of questioning as an impetus for writing texts that present various aspects of a single fact without losing the fundamental characteristics of journalism (such as relevance, public interest, and social responsibility). These characteristics can be seen in high-quality information dissemination (Morgan et al., 2018).

Thus, when aiming to implement this approach, we must consider the interpretation of Manacorda (2007), who states that schools change as the nature and purpose of science change. In this context, the author argues that the process of personal development is transformed, changing the contents and means of everyday production "from the immediate instruments of writing to the types of texts and even the most complicated teaching machines. However, this is extremely slow with an inevitable delay in the transformations of science and technology directly related to production" (Manacorda, 2007, p. 27). New content is then incorporated into traditional structures and relationships. According to this author, schools remain undecided between fulfilling a duty to educate people with specialized knowledge or to cultivate disinterested consumers of culture.

One of the paths proposed in this analysis, which comports with the interpretation of Manacorda (2007), is the mediation of scientific content through printed and digital journalistic texts, internet platforms, social networks, contents, projects, and scientific dissemination activities. Such an approach includes using natural language, easy-to-understand words, dynamic activities, active methodologies in the classroom, and strategies for promoting the involvement of students with the context of the programs' subject matter (Galvão et al., 2020). In this way, several strategies are used to facilitate the understanding of subjects often considered complicated and demotivating by students, especially those related to the traditional sciences, such as chemistry, physics, and biology. This approach can also arouse students' curiosity and aid in encouraging student autonomy (Berbel, 2011; Valente, 2018; Boillos Pereira et al., 2019), when discussing active methodologies. Therefore, the question of how to include these strategies in the educational context arises.

Among the texts that must be used in the promotion of research in classrooms and informal educational spaces are those that belong to the scientific dissemination genre and those that embody the practices of scientific journalism. According to Bueno (2013), the concepts of scientific dissemination and scientific journalism involve communicating science to laypeople, who are part of a broad audience and often do not understand the basic sciences or may even have difficulty understanding the Portuguese language. The aim of such communication is also to popularize science in educational environments. Even in the joint interpretation and analysis of scientific journalism texts along with scientific texts meant for a broad audience, cooperation between the educator and the student is necessary. According to 
Targino (2001), Bueno (2010), and Caldas (2010), professors must strive to do more than merely reproduce content, acting as journalists or communicators at mainly public education and technology institutions, and avoid assuming the unique and exclusive role of scientific translators, since they are the mediators of the process.

Therefore, some questions arise regarding which space scientific dissemination and scientific journalism occupy in the research guidelines of Institution A and Institution B and how to devise strategies to include them in the everyday educational context. Thus, this research was conducted with the aim of analyzing the presence of scientific dissemination and scientific journalism in institutional normative documents, especially those guiding scientific research at these institutions, as well as outlining proposals for including these practices in the teaching, extension, and research actions of these institutions.

\section{Methodological path}

This is a bibliographic, documentary study using a descriptive, qualitative approach based on a case study. According to Marconi and Lakatos (2018), documentary research is characterized by the collection of data from contemporary, primarily written, documents. In this study, the identification, analysis, and theoretical/conceptual treatment of the official and administrative publications of these institutions are prioritized. Therefore, this study was based on discussions among authors on scientific dissemination, scientific journalism, science communication, the curricula of these institutions, and the work of those who view research as an educational principle, such as Bueno (1985, 2010, 2013, 2019), Caldas (2010), Machado (2010), Ramos (2012), Stecanela and Williamson (2013), and Targino (2001). The articles used in the bibliographic research were mainly published between 2008 and 2018 and were collected from the Coordenação de Aperfeiçoamento de Pessoal de Nível Superior (Capes) Journals Database (Capes Journals Platform).

While conducting the documentary research, we identified the two key documents guiding institutional management: the Institutional Development Plan of Institution A (2019d) and the IDP of Institution B (2018). They were prepared and implemented according to legal guidelines on the creation of IDPs, including Law No. 9.394/1996 (LDB), Decree No. 5.773/2006, and Law No. 10.861/2004, in effect from 2019 to 2023. The Institutional Pedagogical Political Project (IPPP - Institution A) and the Institutional Pedagogical Project (IPP - Institution B) were updated in 2018. The research draft and graduate program policy as well as the norms of scientific initiation at these institutions were also analyzed. The aim was to identify the presence (or absence) of scientific dissemination in the form of pedagogical actions and practices focused on the dissemination of scientific knowledge and research to the general public in these documents. We also determined whether these practices, which must be developed by the academic community, and the work of the social communication sectors of these institutions had been integrated.

We also investigated whether the proposals in the documents of the IFs comported with the proposal for the popularization of science through the Action Plan in Science, Technology, and Innovation for Popularization of Science in Brazil (MCTIC, 2018). This document was selected because there is no national policy for promoting scientific dissemination, only documents meant to guide actions in this area. We also analyzed the statute of the Oswaldo Cruz Foundation (Decree No. 8.932/2016) because this entity contributes to scientific research and dissemination throughout the country.

The context of research in the educational environment

Research allied with teaching is present in the ideals of those who seek an education that provides lasting benefits to students. As Machado (2010) and Ramos (2012) state, engaging in research that involves the problematization of a phenomenon, fact, or object leads students to perform a didactic action to "unveil its essence", since such engagement by students requires the integration of the real world with educational content (Hanney and Skirkeviciutey, 2019). The problematization of phenomena lends itself to the development of an integrated curriculum, as it elucidates the scientific, technological, economic, and historical principles of the phenomena under investigation, contributing to the development of students who understand the parts that constitute the whole.

The study conducted by Ramnarain and Moleki (2017) on the use of newspaper articles by teachers in elementary-school classes in South Africa, a practice that also includes the integration of research and teaching, provides exciting implications. The results indicate that the use of scientific articles in the classroom is closely related to the construction of critical thinking skills and humanistic development among both teachers and students. This practice evens makes scientific content seem less abstract to students, leading them to become more invested in science, technology, and the needs of society. Moreover, this approach changes the role of the teacher from that of a transmitter of knowledge to that of a facilitator of learning.

Research is present in both informal educational contexts, such as museums and fairs, and in formal spaces, such as public and private educational institutions and scientific events. In the free, public education offered by federal institutions, 
research traverses scientific, technological, and cultural knowledge. This view is in line with that of Gouvêa (2015), who states that the dissemination and integration of knowledge by society are necessary to transform social relations.

In this context, we consider scientific dissemination and one of its branches, scientific journalism, important tools in the efforts to include research in the everyday educational context, making subjects considered difficult more palatable to students and stimulating their interest in science. According to Bueno (1985), scientific journalism has six functions: informative (disseminating facts and information about science and technology); educational (presupposing that journalists must serve the needs of society and including the functions of informing, training, and raising the awareness of the public); social (situating information about science, technology, and innovation (ST\&I) in broad contexts); cultural (acting in favor of the preservation and enhancement of national culture); economic (enhancing the relationship between scientific development and the productive sector); and political-ideological (aiding in the establishment of a national policy of knowledge generation). Although this research serves diverse purposes, social and educational perspectives are prioritized throughout it.

Thus, scientific dissemination is a way of returning not only material investments but knowledge of the benefits and harms of scientific discoveries from academia to people's everyday lives. It is a way to democratize access to scientific knowledge and increase the scientific literacy of individuals (MCTIC, 2018). It also allows the entire research process to gain support through the recognition of knowledge that must be disclosed to society, making it an indispensable element of research. This joint work between researchers and society requires a constant dialogue to facilitate the learning process, the development of research projects with well-defined objectives, and the participation of professors and students in research. Texts, journalistic articles and reports, and scientific dissemination and journalism articles are necessary instruments for presenting scientific knowledge to the public. The aim of scientific dissemination is to share knowledge, developing the public's ability to question information, which, for Demo (2011), is the primary characteristic of science. According to this author, if one does not question findings, he or she does not understand material and merely reproduces it. Therefore, we present the inclusion of science communication in the educational environment as an indicator of the institutionalization of scientific dissemination in IFs in the state of Goiás.

\section{Where is scientific dissemination in the official documents?}

One of the first proposals to institutionalize scientific journalism and scientific dissemination in the public educational institutions that were analyzed called for the inclusion of these two practices in the official documents guiding IFs and in the normative documents of research, which are as important as the former, strengthening the research actions and work performed in the everyday educational context. Thus, these factors must be considered in the development of a policy so that proposals and actions can be implemented effectively, especially when such communication acts as a mediator in the teaching-learning process of science-related content.

This intermediation is a viable option among young people since, according to a recent study titled What do young Brazilians think of science and technology? (Massarani, Castelfranchi, Fagundes, Moreira and Mendes, 2019), they are interested in issues related to science and technology. In this study, the public perception of science is considered an important factor in identifying processes of dissemination and appropriation of technical and scientific knowledge and seeking mechanisms for promoting citizen participation in ST\&I (Massarani et al., 2019). This was the first study to include measurements of more than opinions, including information about access to knowledge and perceptions of "fake news" and controversial scientific theories. Throughout the country, 2,206 young people aged 15 to 24 years participated in the study.

The most relevant findings were that the environment (80\%), medicine, and health (74\%) are the science-related subjects that arouse the most interest among young people. Issues related to S\&T (science and technology) are also more interesting to them than sports. A total of $67 \%$ of the participants reported being "very interested" in these subjects (Massarani et al., 2019). When asked about people with whom they discussed topics related to S\&T, 44\% answered that they first exchanged ideas with their teachers or professors. This may indicate that the school environment plays a decisive role in the exchange of information and knowledge of S\&T by students and encourages the development of scientific research by young people. In response to this question, friends ranked second (41\%), followed by other relatives $(21 \%)$.

The question of how young people consume science-related content remained. Most of them reported doing so using digital means, such as Google (79\%), followed by videos posted on YouTube (73\%) and WhatsApp (50\%), with the last channel considered the least reliable option by the respondents. Professors and teachers were considered the most reliable source, selected by half of the students, followed by doctors (37.2\%) and scientists at universities or public research institutes (36.7\%). Journalists ranked fourth, selected by $24.2 \%$ of respondents. The level of interest among young people in science-related professions is promising: $84 \%$ of them reported that they consider this profession "very attractive" or "attractive." Despite their interest, they consider pursuing this profession "difficult" or "very difficult" (93\%). 
These data show the importance of professors and teachers in encouraging scientific research, as they appropriate and disseminate reliable content in the field of scientific research, promote dialogue with young people, and act as the main channels for disseminating information. It is undeniable that the process of searching for information currently takes place mainly through digital media, but such information must necessarily pass through channels that have credibility, be they institutional ones or individuals who are considered credible by young people. Thus, we can infer from these results that the misconception that becoming a scientist is impossible is far from being overcome, as this belief seems to endure. Therefore, programs, projects, and actions aimed at bringing knowledge of science to the public must show not only what is being produced, but how, what the role of scientists is, and how to conduct research, as well as the positive and negative aspects and the successes and failures of the scientific process. This would debunk a belief that is deeply rooted in our society: that becoming a scientist is unattainable. As Noy and O'Brien (2019) state, the more science is discussed in education, the more society tends to trust it. Similarly, scientific activities are strengthened as the relationship between education and science is strengthened.

Therefore, scientific dissemination and, consequently, scientific journalism can contribute in two main ways to consolidating research at federal institutes and bringing knowledge of science to young people: by encouraging the use of journalistic articles, magazines, television programs, internet sources, videos, and scientific journalism content in the classroom and enhancing media coverage of science and technology (Bueno, 2013). We believe that guidelines must be officially outlined in the documents analyzed in the present article for this to occur incisively and systematically and to ensure that this approach is linked to outcomes and that attention is paid to these issues when formulating institutional policies, projects, and actions.

\section{Scientific dissemination in the official documents of Institution A}

The initial results published in this study were obtained through qualitative analysis of the occurrence of the terms "communication/communicational", "disseminate/dissemination", "scientific dissemination", "knowledge diffusion", "scientific knowledge dissemination", "scientific knowledge", and "scientific journalism". We searched for these terms in the IDP and IPPP that were updated in 2018; drafts of the Research, Innovation, and Graduate Policies (2019a, 2019b, 2019c); and the regulations of the Scientific Initiation, Technology, and Innovation Scholarships Program (SITISP) of Institution A (2016). After completing our first evaluation of the frequency of their occurrence, we synthesized the significance and meanings associated with these phrases, determining in which titles and passages of the documents they were present. We focused on searching for proposals that included scientific dissemination that would result in the emergence of actions and integrative practices in the everyday contexts of IFs so that we could propose strategies to encourage such practices. These initial points are not extensively addressed in this study, but this is the first step in establishing connections between teaching, research, extension, scientific dissemination/journalism, and the popularization of science. We present in Table 1 the frequency of occurrence of the terms mentioned above, and, in Table 2, we present their significance to Institution A.

Based on the items shown above, we can conclude that there may be some difficulty in understanding what constitutes a work of scientific journalism or an example of scientific dissemination aimed at the general public, or, rather,

Table 1. Frequency of occurrence of terms in IFG institutional documents.

\begin{tabular}{|c|c|c|c|c|c|c|}
\hline Terms & $\begin{array}{l}\text { IDP } \\
(2018)\end{array}$ & $\begin{array}{l}\text { IPPP } \\
(2018)\end{array}$ & $\begin{array}{l}\text { Research } \\
\text { Policy } \\
\text { Draft } \\
\text { (2019) }\end{array}$ & $\begin{array}{l}\text { Innovation } \\
\text { Policy } \\
\text { Draft } \\
\text { (2019) }\end{array}$ & $\begin{array}{l}\text { Graduate } \\
\text { Programs } \\
\text { Policy } \\
\text { Draft } \\
\text { (2019) }\end{array}$ & $\begin{array}{l}\text { Regulation - } \\
\text { PBICTI } \\
\text { (2016) }\end{array}$ \\
\hline $\begin{array}{l}\text { Communication/ } \\
\text { Communicational }\end{array}$ & 39 & 5 & 0 & 0 & 0 & 0 \\
\hline $\begin{array}{l}\text { Disseminate/ } \\
\text { Dissemination }\end{array}$ & 21 & 3 & 0 & 0 & 1 & 1 \\
\hline Scientific dissemination & 0 & 0 & 0 & 0 & 0 & 0 \\
\hline $\begin{array}{l}\text { Diffusion/Dissemination of } \\
\text { Knowledge/Knowing/ } \\
\text { Scientific process }\end{array}$ & 13 & 37 & 1 & 0 & 1 & 0 \\
\hline Scientific knowledge & 2 & 2 & 0 & 1 & 0 & 0 \\
\hline Scientific journalism & 0 & 0 & 0 & 0 & 0 & 0 \\
\hline
\end{tabular}

Source: Prepared by the authors (2020). 


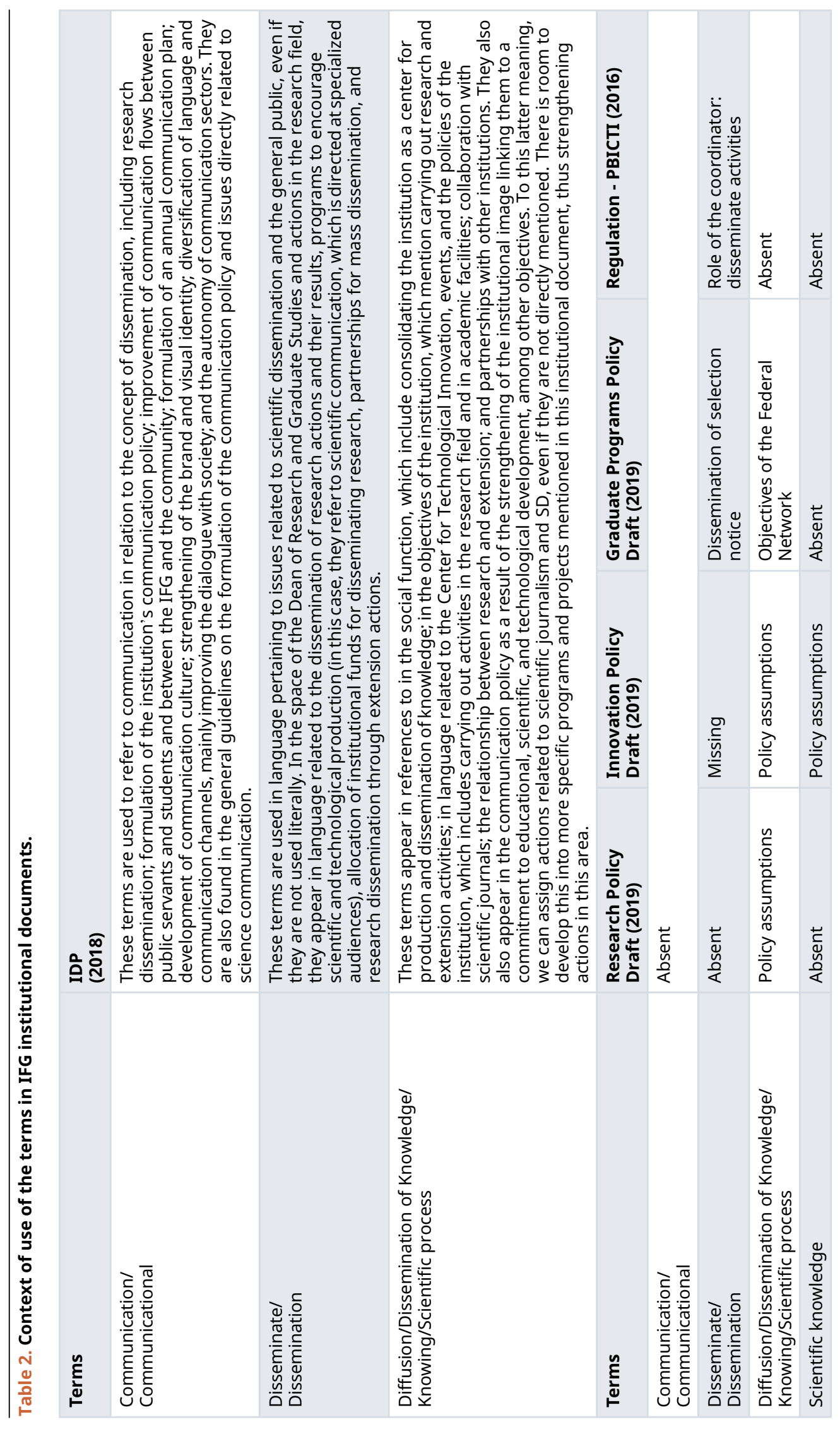




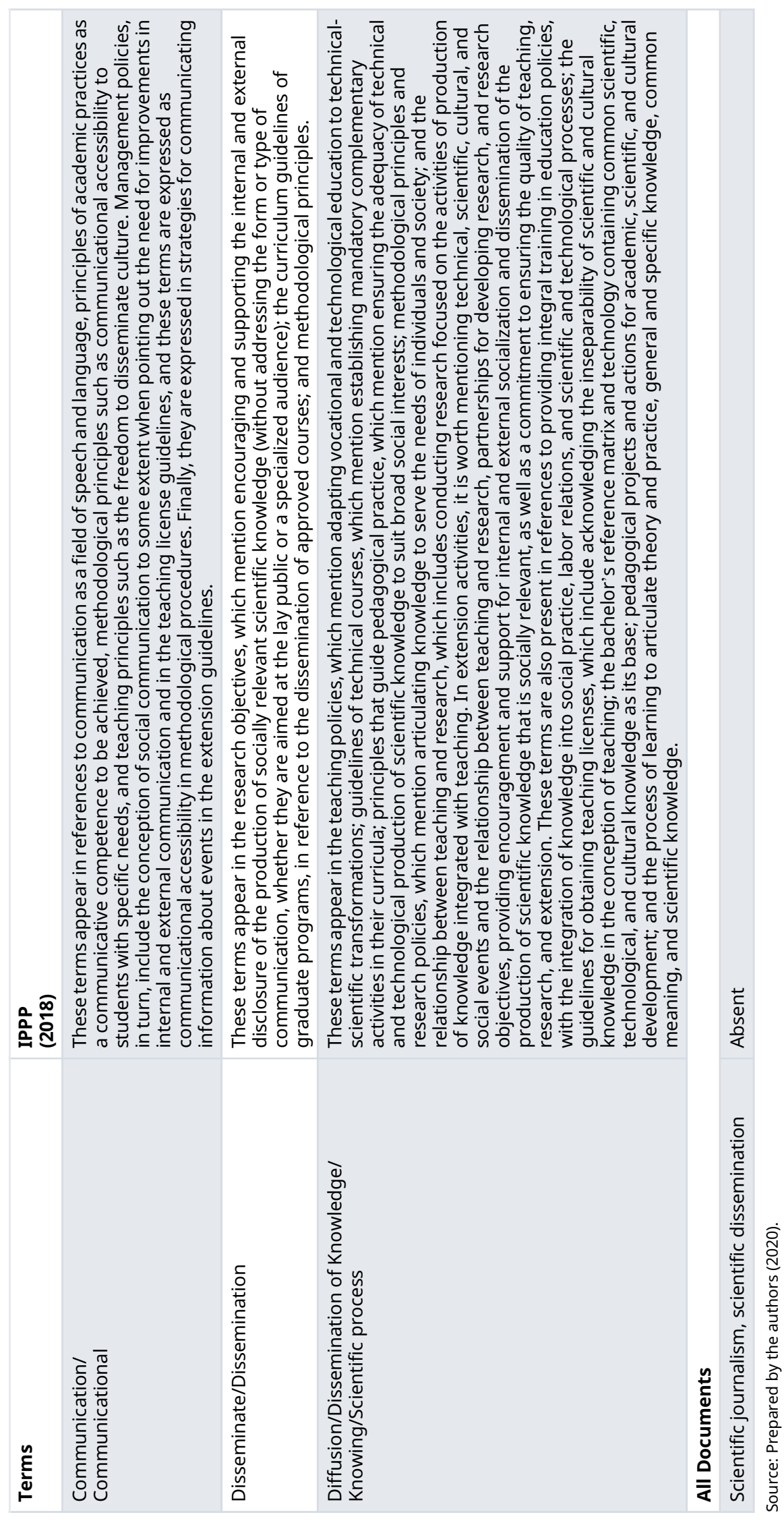


what constitutes scientific production for specialized audiences, like scientific articles, journals, and scientific journals. Therefore, we could not delimit the concept of "popularization of science" as we had first envisioned.

When searching for "diffusion/dissemination of knowledge/knowing/scientific process" and "scientific knowledge" in the IDP, we found 15 instances. These terms appear in references to the social function of the institution, consolidation of the institution as a center for production and dissemination of knowledge, the objectives of the institution, research and extension activities, the Center for Technological Innovation, events, the institution's policies, actions in the research field, academic facilities, collaboration with scientific journals, the relationship between research and extension, and partnerships with other institutions.

These terms also appear in the communication policy, with the strengthening of the institutional image linking it to a commitment to educational, scientific, and technological development, among other objectives. To this category, we can assign actions related to scientific journalism and scientific dissemination, even if they are not directly mentioned. There is room to develop this into more specific programs and projects mentioned in the institutional document, thus strengthening the institution's actions in this area. In general terms, we can say that the IDP can accommodate more consistent scientific dissemination projects and practices, scientific journalism, science communication products for internal and external audiences, and the creation of specialized channels. However, a more comprehensive study addressing the possibilities of integrating the communication sector with the sectors that promote and manage institutional research and promoting dialogue with the academic community is necessary. The terms "scientific dissemination" and "scientific journalism" did not appear explicitly in this plan.

Since the IPPP is a document that addresses education explicitly, few occurrences of "communication/communicational" and "dissemination/disseminate" were found. In the former case, there were only seven occurrences, and not all referred to social communication, with most of them addressing communication as a field of speech and language, as shown in Table 2. In this first part of the document, the term "communication for the dissemination of science" is absent. Language referring to "diffusion/dissemination of knowing/knowledge/scientific process" is predominant in the IPPP. There were 37 instances of these terms, and they are present in several passages. The main references to these terms in the context of this research are shown in Table 2.

Here, we understand that the documents guiding research activities at the institutions we analyzed are still in the drafting and discussion stage and will be finalized later. It is noteworthy that there is no relevant mention of any of the terms we searched for in the regulations regarding scientific initiation, with the proposals addressing the subjects only superficially. They do not even disclose the final work of the research report, whose delivery is mandatory at the end of the IC program through the presentation of an abstract that is clear and is written in accessible language.

An example of language related to scientific dissemination in an official document appears in the statute of the Oswaldo Cruz Foundation (Fiocruz), which is a historically well-known Brazilian institution dating back to 1970 that assigns greater importance to this area than other institutions. Fiocruz's Canal Saúde is responsible for "promoting public debate, social participation, and the dissemination of projects and activities of interest in the areas of health, the environment, science, and technology in healthcare" It is also responsible for the following:

planning, coordinating, supervising, and executing activities related to the development of studies and research related to the history, scientific dissemination, and cultural heritage of health, science, technology, and other related fields, as well as dissemination and education in science, technology, and health (Fiocruz, 2016, p. 7).

Therefore, it is possible to conclude that scientific dissemination can be included in macro documents linked to institutional competences as well as in various areas and actions related to teaching, research, and extension. The aim of including such language in official documents is to guide the development of specific policies and programs for the dissemination and popularization of science by outlining requirements and commitments, always considering the dialogue between communication sectors and the academic community in the dean's office and on campuses.

\section{Scientific dissemination in the official documents of Institution B}

Just as in Institution A documents, we searched for the terms "communication/communicational", "disseminate/ dissemination", "scientific dissemination", "knowledge diffusion", "scientific knowledge dissemination", "scientific knowledge", and "scientific journalism" in the IDP, IPP, the general regulations of graduate and specialization programs, and in the scientific initiation programs at Institution B. We must note that the searches and analyses of the first two documents were performed together, considering that the "plan" and "project" were included in a single file divided into chapters. Table 3 shows the frequency of occurrence of the terms in the documents, and Table 4 shows their main contexts. 
Table 3. Occurrence of terms in IF Goiano institutional documents.

\begin{tabular}{|l|l|l|l|l|}
\hline Terms & $\begin{array}{l}\text { IDP and IPP } \\
(\mathbf{2 0 1 8 )}\end{array}$ & $\begin{array}{l}\text { Graduate } \\
\text { Programs } \\
\text { Regulation } \\
\mathbf{( 2 0 1 9 )}\end{array}$ & $\begin{array}{l}\text { Specialization } \\
\text { Courses } \\
\text { Regulation } \\
\text { (2017) }\end{array}$ & $\begin{array}{l}\text { Norms of the } \\
\text { Scientific } \\
\text { Initiation } \\
\text { Program } \\
\text { (2010) }\end{array}$ \\
\hline Communication/Communicational & 73 & 2 & 1 & 0 \\
\hline Disseminate/Dissemination & 30 & 2 & 1 & 2 \\
\hline Scientific dissemination & 2 & & & 0 \\
\hline $\begin{array}{l}\text { Knowledge Diffusion/Dissemination/ } \\
\text { Scientific Knowing/Knowledge/Process }\end{array}$ & 40 & 0 & 0 & 0 \\
\hline Scientific knowledge & 0 & 0 & 0 & 0 \\
\hline Scientific journalism & 0 & 0 & 0 & 0 \\
\hline
\end{tabular}

Source: Prepared by the authors (2020).

\section{Table 4. Context of use of the terms in the institutional documents of the IF Goiano.}

\begin{tabular}{|c|c|c|c|}
\hline Terms & \multicolumn{3}{|l|}{$\begin{array}{l}\text { IDP and IPP } \\
(2018)\end{array}$} \\
\hline $\begin{array}{l}\text { Communication/ } \\
\text { Communicational }\end{array}$ & \multicolumn{3}{|c|}{$\begin{array}{l}\text { Courses to be offered; strategic objectives; performance indicators and communication } \\
\text { policy: strategies, information flows, and products. }\end{array}$} \\
\hline $\begin{array}{l}\text { Disseminate/ } \\
\text { Dissemination }\end{array}$ & \multicolumn{3}{|c|}{$\begin{array}{l}\text { Research, graduate programs, and innovation policies; internal and external } \\
\text { dissemination of scientific production, extension programs, and institutional events; } \\
\text { dissemination of research results to the community; contribution to dissemination and } \\
\text { promotion; strengthening of dissemination; guidance to managers monitoring } \\
\text { dissemination; SIBi services. }\end{array}$} \\
\hline $\begin{array}{l}\text { Scientific } \\
\text { dissemination }\end{array}$ & \multicolumn{3}{|c|}{$\begin{array}{l}\text { Purposes and characteristics: development of programs of extension and scientific and } \\
\text { technological dissemination; assurance that SIBi can work towards scientific } \\
\text { dissemination and democratization of information. }\end{array}$} \\
\hline $\begin{array}{l}\text { Diffusion/ } \\
\text { Dissemination of } \\
\text { Knowledge/ } \\
\text { Knowing/Scientific } \\
\text { process }\end{array}$ & \multicolumn{3}{|c|}{$\begin{array}{l}\text { Democratization; socialization of knowledge; integration of knowledge; sharing of } \\
\text { scientific and cultural knowledge; initial and continuing education by meeting the } \\
\text { demands of research; the role of the IF Goiano; extension policies; fostering of scientific } \\
\text { production. }\end{array}$} \\
\hline Terms & $\begin{array}{l}\text { Graduate Programs } \\
\text { Regulation (2019) }\end{array}$ & $\begin{array}{l}\text { Specialization } \\
\text { courses (2017) }\end{array}$ & $\begin{array}{l}\text { Scientific initiation norms } \\
\text { (2010) }\end{array}$ \\
\hline $\begin{array}{l}\text { Communication/ } \\
\text { Communicational }\end{array}$ & $\begin{array}{l}\text { Dissemination of the program } \\
\text { by the Communication Advisory } \\
\text { Office; dissemination approved } \\
\text { by communication vehicles. }\end{array}$ & $\begin{array}{l}\text { Dissemination } \\
\text { of the course by } \\
\text { the } \\
\text { communication } \\
\text { team. }\end{array}$ & 0 \\
\hline $\begin{array}{l}\text { Disseminate/ } \\
\text { Dissemination }\end{array}$ & $\begin{array}{l}\text { Dissemination of the program } \\
\text { by the Communication Advisory } \\
\text { Office; dissemination approved } \\
\text { by communication vehicles. }\end{array}$ & $\begin{array}{l}\text { Dissemination } \\
\text { of the course by } \\
\text { the } \\
\text { communication } \\
\text { team. }\end{array}$ & $\begin{array}{l}\text { Role of the coordinator: } \\
\text { disclosure activities; role of } \\
\text { researchers: dissemination of } \\
\text { research in specialized journals. }\end{array}$ \\
\hline $\begin{array}{l}\text { Knowledge } \\
\text { Diffusion/ } \\
\text { Dissemination } \\
\text { Scientific } \\
\text { Knowledge/ } \\
\text { Knowing/Process }\end{array}$ & 0 & 0 & 0 \\
\hline Scientific knowledge & 0 & 0 & 0 \\
\hline \multicolumn{4}{|l|}{ All Documents } \\
\hline Scientific journalism & \multicolumn{3}{|l|}{ Absent } \\
\hline
\end{tabular}

Source: Prepared by the authors (2020). 
We found that explicit language related to scientific dissemination was present in the documents that were analyzed, unlike in those pertaining to Institution A, from which such references could only be inferred. Although there are only two occurrences of this term in the documents, it is noteworthy that its importance is recognized in the institutional history of the IDP and in the charter of the Library System (IPP), which stipulates the development of scientific dissemination programs. In other words, this requirement is mentioned at the beginning of the first document, and it could not be disregarded by the management or academic body of the institution when establishing actions or goals over the years. Despite this fact, there is no objective delimitation of activities that comply with this stipulation for the next five years, not even in the section related to prediction of the implementation of the institution's communication policy. The only references to scientific dissemination actions that can be inferred from the language in the IDP and IPP are implicitly expressed in the titles.

As already mentioned, scientific dissemination in actions taken in consideration of the inseparability of teaching and research, or research and extension, or teaching, research, and extension, can be included in the next update to these documents. This can be accommodated in the competences and actions of the Dean of Research, Graduate Programs, and Innovation of the SIBi; policies; and the programs and projects of teaching, research, extension, and communication, among others. A notable fact that we consider positive is the presence, even if only in the title of the SIBi, of the Division of Communication, Training, and Culture (DGT\&C). The IPP describes this sector as being responsible for communicating science mainly in a specialized and restricted way that is different from the scientific dissemination that we advocate in this study. Nevertheless, this issue could be further explored in the joint work between the communication sectors of the institution and the SIBi team to transpose and expand scientific communication (SC) to scientific dissemination.

Like Bueno (2010), we understand that SC necessarily forms part of scientific dissemination-related actions, which means that the two are intertwined. One depends on the other to fulfill the objective of communicating science to society. One of the purposes of the DGT\&C is to "promote cultural and scientific dissemination activities" (https://suap.ifgoiano. edu.br). The existence of a specific sector for addressing what we advocate in this study can have a significant impact on such efforts if we think about actions that can be integrated into various institutional sectors because they transcend the communication sector. Journalists and communicators specialized in the discourse of scientific dissemination and scientific journalism can also be framed in this context, whether in the form of partnerships or by helping institutions to achieve their educational and social purposes, among other objectives.

A second characteristic of Institution B's documents that is worth mentioning is the way they were prepared, that is, the methodology used by the academic community in executing their preparation. The IDP has technical-bureaucratic content, essentially, with some administrative information; thus, we can infer from this analysis that the institution is organized adequately from an academic point of view. The IPP is the base document for institutional management, which effectively outlines Institution B's policies. We can infer that "all" the actions must be connected even if this is not mentioned in the pedagogical project of the institution. This is a means of addressing the formulation of programs and activities, even if they are not directly linked to the teaching sector, as is the case of the scientific dissemination- and communication-related actions to be developed in these areas. Although such nuances may be difficult to perceive, when we analyze the two institutes in depth, we can capture them and observe important, implicit details.

Among the terms that appear most frequently in the documents, the IDP and IPP, are "communication" with 77 occurrences, "scientific knowledge/knowing/process" with 40 occurrences, and "dissemination/disseminate" with 22 occurrences. Most of these terms were present in the IPP. In the IDP, communication appears between courses to be offered at the Ceres and Trindade campuses and between strategic objectives and performance indicators and improvements in internal and external communication flows. Other references are included in the communication policy, such as in the definition of strategies, improvement in information flows, and the delimitation of communication products.

Among the phrases related to "scientific knowledge/knowing/process" and "knowledge diffusion/dissemination" are democratization, socialization of knowledge to contribute to an ethical and solidarity-driven society (historical), and the integration of technical and technological knowledge with pedagogical practices. We emphasize the importance of a humanistic view for the world, promoting the sharing of scientific and cultural knowledge, which can be seen in the description of the role of Institution B and IFs in the documents. In this way, we can infer that there is concern for socializing information and disseminating science, not only through translation but also through knowledge generation. This can also be observed in initial and continuing education courses (ICE), which require attention to be paid to the demands of training (teaching) and scientific and technological knowledge (research) in line with local and regional realities. 
Initially in the IPP, a document that shows adequate consideration of institutional policies, scientific dissemination is included in several areas, such as Research, Graduate Programs, and Innovation policies, which provide a stimulus to the socialization and internal and external dissemination of the scientific production of Institution B. Here, we can perceive the consideration given to establishing policies that promote scientific dissemination. The general inclusion of actions aimed at promoting scientific dissemination to the general public and the identification and improvement of forms of institutional dissemination is also present in extension programs and events. There is a requirement in the research actions, under the aegis of the Dean of Research, Graduate Programs, and Innovation, to "support and monitor the dissemination of research results in the internal and external community and scientific events" (https://suap.ifgoiano. edu.br). At this point, it would be appropriate to expand this dissemination to aspects of science other than results, including details of the production process and continuous communication actions related to each research project. Other actions mentioned in the IPP regarding this topic include contributing to fostering and strengthening the dissemination of research at Institution B, encouraging the guidance of the coordinators and directors of campuses in the production, execution, and monitoring of research programs, and disseminating the resulting scientific production. The other instances refer to the SIBi and the specification of its services.

Therefore, explicit stimuli to the development of actions related to scientific dissemination are enumerated, especially in relation to the topics addressed in this study. We found that the integration of these actions with the work of the social communication sector was lacking and that this sector could enrich and contribute to such activities by making institutional research accessible to several audiences. The development of a program or project promoting a dialogue between the communication and research sectors under the dean and representatives of science departments could represent a concrete means of uniting the academic community and the scientific field. It would also be possible to hold science fairs for the public, allowing students to familiarize themselves with laboratories and ongoing research through exposure to scientific equipment and lectures and external exhibitions in public places in cities, such as parks, zoos, and bars. It would also be possible to hold meetings between journalists, communicators, and researchers; form working groups for creating communicational products showing what is done at institutions and its relevance to people's lives; and disseminate materials in public and private spaces, such as medical and dental offices and places with a lot of foot traffic. A critical advertising medium that generates good results, especially in inland cities, is the "sound car." It would also be possible, through short texts, to disseminate science-related actions and scientific events, among other things, to the public.

It is important to observe the significance of the meanings associated with the word "scientific" (knowledge, knowing, and others) to the role of Institution B in the sharing of scientific and cultural knowledge. The implications of this concept can also be observed in its extension policies, through the construction of bonds with society via the exchange of knowledge and experiences, research development, teaching, and extension and in the inseparability of these areas, along with actions in the areas of scientific, technological, social, artistic, and cultural innovation. Moreover, such practices would provide an increased stimulus to produce scientific articles for congresses, seminars, and science-related events. In this context, it is apparent that a path of dissemination and scientific journalism should be followed, complementing what is set out in the institution's documents. It is evident in this part of the plan and project that this message is directed at researchers and scientists without the intent of reaching the lay public.

When we talk about the "communication" present in the IPP, we seek the meanings that directly concern the institution's dialogue with society in an expanded form. Despite this term having the largest number of occurrences, not all refer to the communicational form that is addressed in this study. Many were found in the titles of methodologies, which pertain to information and communication technologies or refer to the education policies addressing the interpersonal communication or communication between professors and students, and communication courses to be offered, among other such things, or to the competences of the institutional communication sectors. Thus, such titles refer to general requirements and not to science communication inside or outside the institution.

Finally, when we consider scientific dissemination integrated with teaching, the documents of the two institutions do not address the work of scientific dissemination directly. Instead, there are implied forms of a direct link between teaching and research activities. Although this inseparability can be seen in the guiding documents of the policies, programs, projects, and actions in the academic environment of these institutions, the language that is used is not directly related to the use of instruments of scientific journalism or scientific dissemination in the classroom. These two expressions are not found in the IPPP, IDP, or other Institution A documents. They appear twice in Institution B's documents, but in a restricted way, as has already been mentioned in the analysis of Institution B. Nevertheless, there seems to be room to insert these practices into the norms and guidelines of teaching, especially in relation to the topics referring to research and its direct connection with educational practices and the intersection between teaching and research, between research and extension, and between teaching, research, and extension. 
By drawing a parallel with the Action Plan in Science, Technology, and Innovation for Popularization and Dissemination of Science and Technology (MCTIC, 2018), we can observe that, despite the fact that mechanisms such as including technological projects in extension activities (IFG, 2019e) and holding fairs and exhibitions as extension activities of the IF Goiano are present in the IPPP and IPP it is necessary to further develop the teaching, research and extension triad. This would allow the execution of the proposed plan and the appropriation of science and technology by students of these federal institutes.

The objective of the plan, which must be translated into a policy that relates scientific dissemination to institutional priority areas, is to popularize science in the educational context, enabling citizens to improve their lives and generating a more participatory society. In this context, the assumption that scientific dissemination and scientific journalism are practices aimed at returning the resources used in research to the public is fundamental. It can aid in overcoming the quality crisis in Brazilian education. Scientific dissemination is the appropriation of science and technology by Brazilians and it is a cross-sectional action encompassing all federal states (MCTIC, 2018).

\section{Final considerations}

We do not intend to present an exhaustive discussion in this documentary study but rather to promote the understanding that scientific dissemination, scientific journalism, curricula, and research development are inseparable and essential for the consolidation of research at federal institutes throughout the country. Thus, among the data collected from the official documents of Institution A and Institution B, we observed that discreet actions related to scientific journalism tended to be implied in language related to topics that referred to scientific dissemination. Although the term was not explicitly mentioned (in Institution A), we can infer that the institution recognizes the existence and importance of disseminating research results, since this theme is included in titles throughout the IDP and IPPP. Nevertheless, we have concluded that forthcoming editions of these documents must clarify, or at least initiate, a discussion about programs, projects, and actions that associate the process of dissemination with the results of scientific research. Including specific topics related to scientific dissemination in the titles of media, teaching, research, and extension in the documents of the two institutions is also necessary. We also propose that a research group bringing together Institution A and Institution B, which could advance this discussion, as well as a formal network connecting the journalists, communicators, and researchers of these IFs, should be created, thereby broadening the flow of communication with the local, regional, and national press.

We understand that such dissemination efforts should always be aimed at a lay audience. This means that the proper treatment of information will be necessary; therefore, even in the initial stages, it will be essential to establish a dialogue and joint effort between journalists, communicators, and researchers through such official plans. Therefore, we suggest that in-depth studies be conducted on this subject so that our suggestions can be implemented in updates to the documents of Institution A and Institution B. It is important to consider officially documenting the guidelines to be followed and policies to be formulated and putting them into practice. This would allow the inclusion of the culture and practices of scientific journalism and science dissemination and publicize the work of these institutions and the other public educational institutions of the Federal Network of Professional, Scientific, and Technological Education, exposing the public to the scientific work they are carrying out.

\section{Data availability}

All data underlying the results are available as part of the article and no additional source data are required.

Berbel NAN: As metodologias ativas e a promoção da autonomia de estudantes. 2011. [Active methodologies and the promotion of student autonomy]. Semina: Ciências Sociais e Humanas. 2011; 32(1): 25-40.

Reference Source

Boillos Pereira M, Pérez-Izaguirre E, Apaolaza-Llorente D: Systems of Augmentative and Alternative Communication (SAACs) in Spain: A Systematic Review of the Educational Practices Conducted in the Last Decade. Social Sciences. 2019; 8(1), 15. Publisher Full Text

Bueno WC: Jornalismo científico: conceitos e funções. [Scientific journalism: concepts and functions].Ciência e Cultura. 1985; 37(9):

$1421-1427$

Reference Source
Bueno Wc: Comunicação científica e divulgação científica: aproximações e rupturas conceituais. [Special Issue] [Scientific communication and scientific dissemination: conceptual approaches and ruptures]. Informação e Informação. 2010; 15(1), 1-12.

Reference Source

Bueno WC: A formação do jornalista científico: além da competência técnica. [The formation of the scientific journalist: beyond the technical competence]. In: Porto CM, Bortoliero S (Eds.). Jornalismo, ciência e educação: interfaces. 2013; (pp. 13-24). Salvador, BA: EDUFBA. Bueno WC: 0 jornalismo científico no século XXI: desafios e tendências. Scientific journalism in the 21st century: challenges and trends. 2019. São Paulo, SP: Curso de Jornalismo Científico. Comtexto Comunicação e Jornalismo a Distância.

Reference Source 
Caldas G: Divulgação científica e relações de poder. [Special Issue] [Scientific dissemination and power relations]. Informação e Informação. 2010; 15(1), 31-42.

Reference Source

Demo P: Educar pela pesquisa. [Educate through research]. Campinas, SP: Autores Associados; 2011.

Galvão T, Felicio CM, Ferreira JC, et al.: Scientific Journalism as an Educational Practice: An Experience Report of the Collective Construction of a "Science Clothesline". Science Communication. 2020; 00(0), 1-12.

Publisher Full Text

Gouvêa G: A divulgação da ciência, da técnica e cidadania em sala de aula. [The dissemination of science, technique and citizenship in th classroom]. In: Giordan M, Cunha MB (Eds.). Divulgação Científica na Sala de Aula. 2015; pp. 13-41. São Paulo, SP: Unijuí.

Gramsci A: Cadernos do Cárcere. Volume 2: Os Intelectuais. O Princípio Educativo. Jornalismo. Dail Notebooks. Volume 2: The Intellectuals. The Educational Principle. Journalism]. Translation Nelson Coutinho. Rio de Janeiro, RJ: Civilização Brasileira; 2004.

Hanney R, Skirkeviciutey G: Reflection, identity, community: Affordances of blogging for social interaction and reflective dialogue. Education and Information Technologies. 2019.

Publisher Full Text

Machado L: Ensino médio e técnico com currículos integrados: propostas de ação didática para uma relação não fantasiosa. [High school and technical with integrated curricula: proposals for didactic action for a non-fanciful relationship]. In: Moll J (Ed.). Educação Profissional e Tecnológica no Brasil Contemporâneo. 2010; (pp. 80-95). Porto Alegre, RS: Artmed.

Manacorda MA: Marx e a pedagogia moderna. [Marx and modern pedagogy]. Translation Newton Ramos de Oliveira. Campinas, SP: Alínea; 2007.

de Marconi MA, Lakatos EM: Fundamentos de Metodologia Científica. [Fundamentals of Scientific Methodology]. São Paulo, SP: Atlas; 2018. Massarani L, Castelfranchi $Y$, Fagundes V, et al.: O que os jovens brasileiros pensam da ciência e da tecnologia? [What do young Brazilians think of science and technology? (Resumo Executivo). Rio de
Janeiro, RJ: Instituto Nacional de Ciência e Tecnologia em Comunicação Pública da Ciência e Tecnologia (INCT-CPCT - Brazil); 2019. Reference Source

Morgan M, Collins W, Sparks G, et al.: Identifying Relevant Anti-Science Perceptions to Improve Science-Based Communication: The Negative Perceptions of Science Scale. Social Sciences. 2018; 7(4): 64.

Publisher Full Text

Noy S, O'Brien TL: Science for good? The effects of education and national context on perceptions of science. Public Understanding of Science. 2019; 28(8): 897-916.

Reference Source

Ramnarain U, Moleki B: Teachers' Use of Newspaper Articles in Promoting a Humanistic Perspective of Science in South Africa. J Science Teacher Education. 2017; 28(2): 205-217.

Publisher Full Text

Ramos M: Possibilidades e desafios na organização do currículo integrado. [Possibilities and challenges in organizing the integrated curriculum]. In: Frigotto G, Ciavatta M, Ramos M (Eds.). Ensino Médio Integrado: Concepção e Contradições. 2012; (pp. 107-128). São Paulo, SP: Cortez.

Stecanela N, Williamson G: A educação básica e a pesquisa em sala de aula. [Basic education and classroom research]. Acta Scientiarum

Education. 2013; 35(2): 283-292.

Reference Source

Targino MG: Divulgação de resultados como expressão da função social do pesquisador. [Dissemination of results as an expression of the researcher's social function]. Intercom: Revista Brasileira de Ciências da Comunicação. 2001; 24(1): 11-35.

Reference Source

Valente JA: A sala de aula invertida e a possibilidade do ensino personalizado: uma experiência com a graduação em midialogia. [The inverted classroom and the possibility of personalized teaching: an experience with graduation in medialogy]. In: Bacich L, Moran L (Eds.) Metodologias ativas para uma educação inovadora: uma abordagem teóricoprática. 2018; (pp. 26-44). Porto Alegre, RS: Penso. 
The benefits of publishing with F1000Research:

- Your article is published within days, with no editorial bias

- You can publish traditional articles, null/negative results, case reports, data notes and more

- The peer review process is transparent and collaborative

- Your article is indexed in PubMed after passing peer review

- Dedicated customer support at every stage

For pre-submission enquiries, contact research@f1000.com 